\title{
Exchange of new ideas: towards a more open, cooperative and sustainable world
}

\author{
Johannes (Joost) PLATJE, WSB University in Wroclaw, Wroclaw, Poland \\ Grahame FALLON, Brunel University, London, United Kingdom \\ Mehmet Baha KARAN, CEVI \& Hacettepe University, Ankara, Turkey \\ Wim WESTERMAN, University of Groningen, The Netherlands
}

Yoram KROZER, Sustainable Innovations Academy, Amsterdam, The Netherlands

Markus WILL, University of Applied Science Zittau/Görlitz, Germany

Katarzyna KUREK, Johan VAN OPHEM, Wageningen University \& Research, The Netherlands

\begin{abstract}
:
Aim: Provide a summary of the expressed views, presentations and discussions during the ISINI14 (2020) online conference.

Design: Next to rather traditional but this time online presentations, the discussions not only took place by way of oral communication, but also via an online tool. The administrators of the conference prepared in a word-processing programme a framework, where the participants could enter issues, questions and comments in real time, and react to each others writings. These issues, questions and comments were also discussed orally. The results of the exchange of new ideas are presented below, and should provide an impulse for further discussion at ISINI online meetings in the future.
\end{abstract}

Correspondence address: Johannes (Joost) PLATJE, WSB University in Wrocław, ul. Fabryczna 29-31, 53-609 Wrocław, Poland. E-mail: johannes.platje@wsb.wroclaw.pl (Johannes (Joost) PLATJE), grahame.fallon@brunel.ac.uk (Grahame FALLON), mbkaran@hacettepe.edu.tr (Mehmet Baha KARAN), w.westerman@rug.nl (Wim WESTERMAN), krozer@xs4all.nl (Yoram KROZER), m.will@hszg.de (Markus WILL), katarzyna.kurek@wur.nl (Katarzyna KUREK), johan.vanophem@wur.nl (Johan VAN OPHEM).

Received: 29.09.2020, Accepted: 29.09.2020

doi: http://dx.doi.org/10.29015/cerem.891 
Findings: In order to achieve sustainable development, protect democratic values and empower citizens in different countries with a different institutional setting, a sound balance between open markets and sound regulation should be struck at various levels. Global and regional (EU) cooperationis needed for solving challenges to sustainable development - e.g. in relation to unexpected events such as the COVID-19 pandemic and climate (change) as a kind of public good.

Keywords: new ideas, empowerment, climate change, COVID-19, European Union, decision making process, risk management, sustainable development

JEL: D70, D81, F02, Q01, Q54

\section{Introduction}

The $14^{\text {th }}$ conference of the International Society of Intercommunication of New Ideas (ISINI 2020, see www.isini.info) was held online. While online discussions do not have the charm of life discussions (where coffee breaks are an important element of free and creative discussion), it will be necessary to use this instrument in both the nearby and also the later future.

This is not only for reasons related to the uncertainty regarding to COVID-19 and future pandemics, but also due to the action needed in the framework of proactive climate policy. While poorer countries and areas may face troubles with access to the Internet (infrastructure, hardware), online meetings may facilitate participation for people without funding and difficulties with obtaining a visa for, e.g., EU countries.

It is a challenge to create interesting discussions that are also providing the necessary fun and if something goes wrong in terms of use of technology, we can only learn from this. Errors and frictions can be expected when people have different experiences with the multiple tools used. This is a challenge the scientific community needs to deal with, in order to include, among others, scholars with different skills and funding for equipment.

While personal engagement is probably the most important factor for success, the organizers used a simple, additional ,experimental” instrument for discussion - a word file in MS Sharepoint where all assigned participants can write in real time together in the file. Questions, comments and ideas can be put into the file at any moment, this as an alternative to e.g. using the chat function. 
The aim of conference was to discuss about ideas, and ,to create or recreate alternative paradigms that can help to formulate adequate policies to solve [current and future] problems“" (www.isini.info) This requires conducting discussion and posing questions. The description of the exchange of ideas is presented in this article.

The opening speech of the vice president of CEVI (Center for Energy and Value Issues - co-organizer) is presented in Section 2, after which the opening session on COVID-19 and other ingored threats is referred to in section 3. In Section 4 and 5, a summary of the presentations and discussions of the Andries Nentjes Memorial Session (see also "The Legacy of Andries Nentjes" in this issue of CEREM), as well as an outsider view on the EU decision making process can be found. Section 6 concludes.

\section{CEVI views at the ISINI 2020 conference $^{1}$}

We regretfully watch that the world has entered a new era in recent years. Moreover, the pandemic and the ensuing economic recession made the situation worse. While income inequality in the world increased after the 2008 crisis, we observed the rise in populism and support for autocracy, as well as increasing antiglobalization in most countries. Authoritarian and populist leaders as well as administration styles of such countries such as China have become role models.

In this context, it seems unlikely that the world will soon return to the idea of mutually beneficial globalization that defined the early 21 st century. Moreover, without the incentive to preserve the collective gains from global economic integration, the architecture of global economic governance established in the 20th century would rapidly disintegrate. On top of all these developments, like the fall of the Berlin Wall or the collapse of Lehman Brothers (triggering off the financial crisis of 2008), the coronavirus pandemic is a world-shaking event that we can only begin to imagine today.

${ }^{1}$ Opening speech by Prof. Dr. Mehmet Baha Karan, Vice President of CEVI (Center for Energy and Value Issues, https://www.centerforenergyandvalue.org/about.html). 
As many thinkers and scientists have argued, just as this disease has shattered lives, upset markets, and reveals the (lack of) competence of governments, it will lead to permanent changes in political and economic power, which only will become visible later. As Prof. Yuval Harari (2020) points out, we have two important choices to make in this time of crisis. The first choice is between totalitarian surveillance and citizen empowerment, whereas the second is between nationalist isolation and global solidarity. People who fear that they will lose their health or jobs due to the crisis will probably seek strong and authoritarian governments. Developing technology increases the surveillance capacity of the state, curtailing the freedom of individuals. This in turn leads to weakening social and economic institutions, in particular touching the position of the weakest individuals..

However, as Prof. Acemoğlu and Prof. Robinson reveal in their recent book The Narrow Corridor (2019), liberty emerges only when a delicate and precarious balance is struck between the state and society. Both the epidemic itself and the resulting economic crisis are global problems. They can only be solved effectively by international cooperation. Harari advises to choose global solidarity in order to master the COVID-19 crisis as well as future crises that might assail humankind in the 21 st country.

I think that all participants of this conference will prefer citizen empowerment to totalitarian surveillance and global solidarity to nationalist isolation. However, this is not an easy task in a world where people are greedy, self-interested, and have many short-term expectations. Regardless of the field in which they work, scientists and community leaders need to tirelessly demonstrate the importance of international cooperation, collaboration, and consensus. Multinational associations such as ISINI and CEVI should not forget that their existence and development is only possible when international solidarity is seen as superior to national and individual interests.

Not just as a summary of the CEVI contributions at the conference, I like to point at the importance of energy, economics and finance topics separately, jointly and even beyond in the current era. This should be done in a world that takes up civil liberties to, e.g., switching energy suppliers, as well as choosing financing policies. In this world, a mix of conventional and renewable energy is asked for. 
Also, capital investments in general should be carefully planned to make money and a better world.

I believe that the ideas emerging in the course of this conference will strengthen the countries' institutions and global solidarity. Although our efforts are small steps on a worldwide scale, it should not be forgotten that tiny grains of sand come together with large structures.

\section{On COVID 19, Climate Change and other examples of ignored threats (Opening Session)}

"Poking in the Mist", was the title of the keynote speech in the opening session of the conference. As the metaphor suggests, strategic and risk management in organisations is often a 'muddling through' in the face of uncertainty, ignorance, volatility and complexity. It has always been that way, because almost the entire history of mankind can be read as the desire to transform insecurity into security and robust actions. This begins with the flight from the sabre-toothed tiger, and is also the case with the current crisis management of natural disasters and pandemics or the issue of climate change.

So the issue is how robust decisions can be made, justified and legitimised. When predicting extremely rare events (so-called "Black Swans"), we often suffer due to cognitive limitations, or are surprised by the events. This is despite the fact that certain events have either been predicted or at least appear to be expectable. Pandemics, for example, are considered in actuarial science to be an event that can occur every 20 years. ${ }^{2}$ Nevertheless, such events, let us call them "black elephants", are ignored. In fact, there are probably no Black Swans, but rather ignored warning signals (Amyotte et al. 2014)

The discussions in the contribution then focused primarily on the question of the extent to which this ignorance, i.e., the deliberate fading out of catastrophes that

\footnotetext{
2 https://www.handelsblatt.com/finanzen/banken-versicherungen/gunther-kraut-pandemieexperte-der-munich-re-alle-20-bis-30-jahre-kann-so-etwas-wie-coronapassieren/25770456.html?ticket=ST-527058-0edblFrcIrnadfmpii1K-ap4 [10.09.2020].
} 
threaten the existence of a company or the society, is a rational act (see also Will 2020, this issue).

\section{Environmental protection and climate change (Andries Nentjes Memorial Sessions $)^{3}$}

The first presentation ${ }^{4}$ concerned quantitative assessments of the potential carbon leakage under the Paris Agreement. This potential is rather big, especially if the USA does not participate in abatement. Online discussions centered on the reliability of the data and on the institutional mechanisms of the Paris Agreement that may help to foster compliance with the emission targets of countries around the world. Important issues for future research are the inclusion of carbon leakage into the $\mathrm{CO}_{2}$ accounting regarding imports and exports of a country, enabling assessment of the dynamic effects of climate policy.

The second contribution ${ }^{5}$ concerned sustainable development from a long-term evolutionary perspective and the current need for a sustainability revolution. Discussing Glaubrecht's (2019) book on the end of evolution, it was mentioned that history of Homo Sapiens seems to be one of extinction of other species. As this is a difficult to grasp issue, which may easily lead to a nihilistic approach, it was emphasized that there is a need for a range of narratives that could inspire (different groups of) people to engage in sustainable behaviour.

In the online discussion, Schrauwen explained: "I think evolution is simply based on remorseless competition (although "friendly"cooperation is a way to win this competition, too). Diversity is the result of mutations and the fact that very many small niches for specialized species can be found in an ecosystem. I don't believe that homo sapiens is doomed to get extinct and only robots will "survive",

\footnotetext{
${ }^{3}$ The two Andries Nentjes sessions were organized by Edwin Woerdman and Yoram Krozer, former PhD students of Andries Nentjes.

4 Lewis Carl King (Institute of Environmental Science and Technology, Universitat Autònoma de Barcelona, Spain). Partly based on work done together with Jeroen van den Bergh (School of Business and Economics \& Institute for Environmental Studies, VU Amsterdam University, The Netherlands.

${ }^{5}$ Bas Schrauwen, article published in this volume.
} 
like Harari sometimes seems to suggest. Glaubrecht does not say this either. His worst-case scenario is a massive collapse of the human population with some small group of survivors adapting to a then different planet. Humans have proven to be extremely flexible and adapted to many extreme climate changes in the course of their existence as a species. I personally think even a better future is still possible, if we realize a global sustainability revolution, accept that many disasters nevertheless will come and learn to adapt."

However, due to the focus on short-term costs and benefits by most people, organisations and governments, extinction of Homo Sapiens remains "a very probable outcome and from a purely biological and evolutionary perspective it simply is the way things go. We would get extinct along with all the other creatures we have been driving to extinction. It certainly is what is going to happen if we do not take action. ... I honestly believe we still could choose a different path."

In the next presentation, ${ }^{6}$ seven hypotheses were provided capturing the likely development of climate law in the EU. The central hypothesis is that EU climate law will be overtaken by the market, as a result of the quest by entrepreneurs for innovation profits from selling carbon-free technologies. Online discussions focused on the ultimate consequence of EU climate law becoming obsolete due to technical progress as well as on the question whether climate policy can still be effective in case of economic (and energy) growth.

The presentation on fisheries policies in Chile ${ }^{7}$ discussed territorial use rights in fisheries (TURFs). It was shown that fishermen catch less than their quota to increase future quota. Online discussions centered on the difference between TURFs and tradable fisheries quota, which have been abolished in Chile, and how the quite successful TURF system can be nevertheless subject to gaming ('poaching'). The regulator uses a biological model to forecast natural growth (and thus determine the quota) depending on the stock. A problem remains that the quotas did not specify where the fish should be caught. This led to overfishing in particular areas.

\footnotetext{
${ }^{6}$ Edwin Woerdman (University of Groningen, The Netherlands).

${ }^{7}$ Bouwe Dijkstra (University of Nottingham, UK), in co-operation with Juan Rosas-Munoz (University of Bio-Bio, Chile).
} 
The next presentation ${ }^{8}$ provided an overview of opportunities for a just economic transition in the Polish Silesia region, which has to shift from coal mining to low-carbon activities and technologies, such as e-batteries and e-vehicle production. Online discussions stressed the political problem of coal lobbying in Poland, including the resistance to change by trade unions, and also questioned the possibilities to link the region with the automotive manufacturing sector in Germany. As miners are relatively well-paid, phasing out coal mining will probably require strong (financial) incentives to present opposition from the coal miners, being strong stakeholders in the Polish institutional setting.

In the discussion on the presentation on the limits of economic theories and models ${ }^{9}$ it was argued that models are no simplification of reality, as is often argued in economic textbooks. Theories are grounded in worldviews, and as such a social construct, that expresses how we think the world looks like. Thus, a model may become a perceived picture of the world, a partial, simplistic tool used to create policy. Furthermore, as Edwin Woerdman posed it, a question is what are the determinants of the fashion for certain economic theories and models - e.g., after game theory became fashionable among economists, we moved to institutional economics and now we are in a behavioral economics hausse (= adding psychology to economics).

The final presentation ${ }^{10}$ considered the writings of philosophers like Spinoza and Kant to discuss elements of optimism in a time of uncertainty. The presenter warned for the decay of democratic values in society. As such, she confirmed the arguments presented in Section 2 of this article. Online discussions focused on the dangers of having losers from globalization but also on Fukuyama's end of ideology, which theorizes that liberal democracy is the superior form of people's government. An interesting issue for research posed by Edwin Woerdman is that the end of ideology cannot be refuted (liberal democracy) from a rational point of view. It can be

8 Beni Feidler and Shubhra Chaudrhy, presenting a joint study project together with Rozemarijn van Dijk and Pei-Hsin Cheng as students of the EUREC Master Sustainable Energy System Management (SESyM), supervised by Wytze van der Gaast (Hanze University of Applied Sciences, Groningen, the Netherlands).

${ }^{9}$ Hans Visser (VU Amsterdam University),

${ }^{10}$ Ingrid Visser-Roos (Inholland University of Applied Science, Diemen, the Netherlands), 
overthrown in reality by religious and populist irrationality (ISIS, Trump, Putin, etc), so the future of democracy remains uncertain.

\section{EU decision making processes: an outsider view ${ }^{11}$}

For a long time, the so-called democratic deficit in EU decision making processes has been a political issue (Bonde 2011; Sotiris 2017; Sorace 2018). It became a strong element in the Brexit campaign - Take Back Control (Mavrozacharakis et al. 2017; Bell 2017; Alemanno 2020). As emphasized in Section 2 of this article, this is an example of the friction between global solidarity and local co-operation and empowerment, which is fundamental in the discussion on the subsidiarity principle (see Etzioni 2018).

In the discussion, the following issue for research was brought forward. Brexit can be a considered kind of stress-test for the EU. If managed properly, Brexit can only strengthen the EU. When the UK manages it well, then this is a sign that the EU in current form is fragile, or weak, and needs more serious changes than EUoptimists may like. In other words, Brexit might be perceived as an experiment, where failure of the UK leads to positive experience for the EU-27, or to a rearrangement of principles of functioning of the EU.

The panel was organized to take a closer look ar the process of decision making at the EU level (see Figure 1). The standard decision making procedure is based on co-decisioning between the major institutions, i.e., the European Commission, the European Parliament and the European Council. Usually, the legislative initiative is taken by the European Commission. Throughout the decision making process and before the final form of a regulation is approved, the advantages and disadvantages of a possible policy is assessed. The European Commission requests an impact assessment during the second reading, when the draft of the regulation is under

11 This panel was organized and moderated by Katarzyna Kurek (Wageningen University \& Research, The Netherlands), while Grahame Fallon (Brunel University, London, United Kingdom \& WSB University in Gdańsk, Poland) was the discussant. 
review in the European Parliament. The process of the EU decision making includes the engagement of the outsiders, i.e., external stakeholders.

During this panel, four representatives of different stakeholders presented their experience and knowledge in influencing the decision making process at the level of the EU institutions. The purpose of this panel was to bring together external actors like organizations, lobbyists or non-EU countries who regulary deliver their messages to the EU regulatory bodies. Such interactions are particularly needed as anti-EU fractions and the euro-skeptical movements gain strength. Moreover, involvement of stakeholders in the decision making process is a sign of bottom-up involvement in democratic practices. Their major message is actually that there is limited room to influence the decision making processes of the EU institutions, i.e., a democratic deficit exists. In this context, the invited panellists presented how different stakeholders actively engage in the EU decision making process.

\section{Figue 1. How EU bodies work together}

\section{How EU bodies work together}

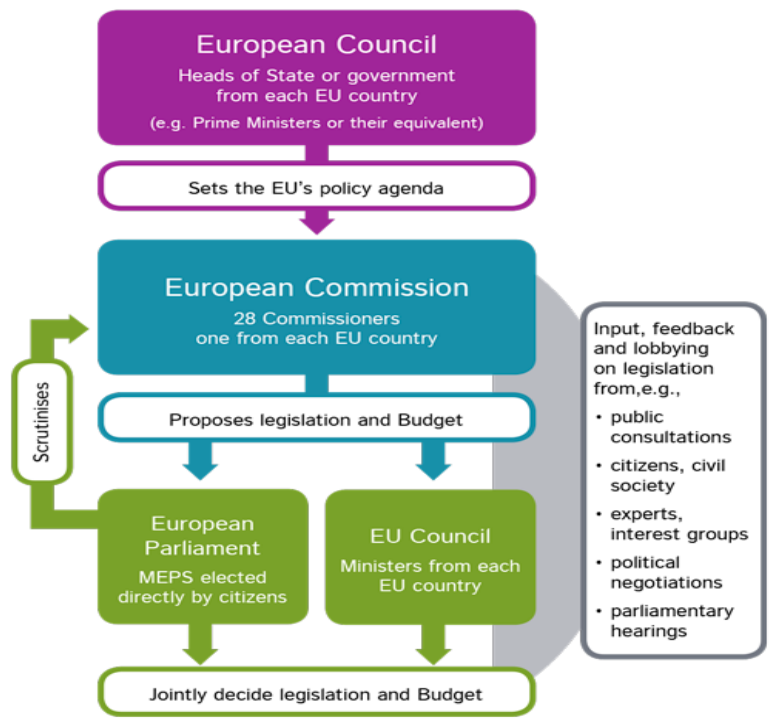

Source: https://www.tasc.ie/opengovtoolkit/public-decision-making/european-union/ 
The first presentation covered the particularly important topic, 'From seating arrangements to legislative procedures: influencing EU decision making processes as a lobbyist' from a highly experienced lobbyist perspective. ${ }^{12}$ A series of key points and issues regarding the basic nuts and bolts of the lobbying process, the main decision makers with whom lobbyists interact, the strategies that lobbyists employ to maximise the impact of their work on EU decision making, and the way in which impact can be maximised given the constraints that lobbyists face in the EU context were outlined and explained. A number of top tips, tricks and considerations that lobbyists should heed and follow in order to maximise their impact on the EU decision making process were presented. It was argued that identification of communication channels and establishing long term relations is crucial to sucessful lobbying processes. In the discussion on the issues, the following was brought forward by one of the participants: "Is lobbying an element of a democratic society? My father used to say that lobbying strengthens specific interest groups, who enrich themselves at the expense of the common citizen. And as a consequence, it can strengthen the perceived democratic deficit."

Other issues requiring research are: (i) Lobbying at EU or member state level which has the greater impact? (ii) What impact have recent EU crises, such as the Eurozone problems, Brexit, COVID-19, etc., been having on the EU lobbying process, and on the most effective strategies for maximising the resultant impact? (iii) How do effective EU lobbying strategies differ, when for example lobbyists are working on behalf of large and small business clients? (iv) Lobbyists usually have a negative perception in the EU ambience. How can be this changed, since they are EU decision making stakeholders too? (v) Are there known flagship case studies of significant lobbyists impact on an EU law? (vi) What are the most desired skills of a successful lobbyist? (vii) What has been the impact of COVID-19 on the decisionmaking processes in the EU institutions and for lobbyists?

The next presenter provided insight into how to optimise interactive innovation and the delivery of EU policies to speed up innovation in rural areas of Europe. The presentation, 'Better rural innovation: linking actors, instruments and policies

${ }^{12}$ Glenn Cezanne (Time and Place Consulting). 
through letworks (LIAISON) ${ }^{13}$ began with an outline of the EU's Liaison project, before going on to explain the division of (EU plus EEA) Europe into four macroregional clusters for interactive innovation study and promotional purposes. On the example of Horizon 2020 agriculture projects, the interactive innovation model was introduced. This is a mechanism developed by the European Commission, aiming at building a dialogue between the citizens and various EU stakeholders. The mechanism is mostly applied in the Western EU member states. The pilot projects are case studies which can support the development, use and application of the interactive innovation model in Central and Eastern European (CEE) countries. The rest of the presentation discussed the meaning of interactive innovation, how it is understood by different actors in the agricultural innovation process, the operation of interactive innovation in the agricultural sphere in the EU/EEA, its development in CEE countries, the evaluation of interactive innovation and key sources of knowledge that had been drawn throughout the project.

In the discussion, the following issues were raised for further elaboration: (i) How are CEE as well as West European agricultural interests reflected in the EU's rural innovation strategy? (ii) How far and in which ways does it provide support for both larger and smaller farmers who wish to implement and improve their innovative practices? (iii) Do the $\mathrm{H} 2020$ projects result in co-designing or impacting EU decision making processes? (iv) Is interactive innovation too difficult to handle for the agricultural sector? It is to a large extent a top-down productionist sector? (v) How about the involvement of citizens in interactive innovation? (vi) Are some sectors projects to be more innovative than others? (vii) Is interactive innovation a kind of sustainable innovation?

The third contribution 'Contribution to the EU decision making process - The perspective of a third country ${ }^{14}$ gave, on the example of Moldova, an informative and thought-provoking introduction to the question: how can the third countries influence the EU's decision making process, aided by partnership arrangements? It was emphasized that there exists the need for the EU to follow the principle of flexibility when creating partnerships with third countries, and that it should tailor

\footnotetext{
${ }^{13}$ Anna Augustyn (Groupe de Bruges).

${ }^{14}$ Aliona Balan (College of Europe).
} 
make its approach to cooperation with each of these countries in order to maximise the resultant political, economic and security benefits. The non-member states countries are involved in decion making processes through dedicated political platforms and organizations. It has been underlined that impact on the EU policies by the third countries is stronger when they cooperate to deliver a joint message. Single actions find less attention at the EU regulatory level. The advocacy function can also be addressed by external programmes such as H2020, FP7, The EU Health Programme and COSME.

In the discussion, a series of related, follow up questions were identified: (i) Which of the Eastern partnership countries is presenting the biggest challenge to EU decision makers, and how is this challenge currently being dealt with? (ii) How effectively are the EU's relations with Russia, the EU's largest and most problematic neighbour, currently being managed? (iii) Taking Moldova as an example, has partnership proved to be a useful stepping-stone on the road towards possible future EU accession? (iv) In which areas of the EU laws are non-members countries mostly consulted? (v) What is Moldova's status in its EU negotiations? (vi) Which organizations in Moldova participate in the EU consultations? Are they any non-governmental civil consultants involved? (vii) Which of the channels of EU cooperation that are mentioned can be found to be the most successful so far?

The final presentation 'Opportunities and obstacles for SMEs regarding EU decision making process in the context of innovations ${ }^{15}$ dealt with the ability of EU (and, in particular Polish) SMEs to engage with the EU decision making process and the support that representatives such as ZPP (The Union of Entrepreneurs and Employers) can give them to help them to manage this interaction effectively. This organization which represents over 50,000 members is not assured a place in the EU regulation process. The role of ZPP is fostering the dialogue between the EU institutions and local organizations. Joint voices of entrepreneurs and employers have a larger probability of being heard by policy makers.

In the discussion, the following questions for deeper elaboration were raised: (i) How much progress has been made towards creating a truly friendly environment

\footnotetext{
15 Agata Boutanos (ZPP - Związek Przedsiębiorców i Pracodawców (Union of Entrepreneurs and Employers)).
} 
for SMEs when dealing with EU decision makers? (ii) How important has been the role of ZPP in helping to create such an environment? (iii) Are the advantages and difficulties created by the EU decision making process and EU regulation greater for innovative CEE and Polish SMEs than for their counterparts in Western Europe? (iv) The role of media / social media for SMEs. (v) How important is the proximity to the EU decision making institutions in the online era? Is a Brussels office a must for an organization like ZPP? (vi) Is the current online work environment an obstacle for the development of ZPP in Brussels? (vii) The need for a Small Business Act for Europe is high! How do organizations like ZPP support the awareness for the small businesses on the European level?

\section{Concluding remarks}

The world is facing huge challenges. Besides the current COVID-19 crisis, climate change, energy provision, increasing inequalities, are only a few example of crises that may hit the world. As a consequence, it may be necessary to change the approach in economic research. For example, in a discussion on the liquidity of the enterprise in normal and crisis times, it was asked whether we shouldn't start to talk about crises being the norm. This implies that liquidity, like other economic indicators of the company, should be crisis proof. From the point of view of consumers, like with governments, the current debt rates and lack of savings make them vulnerable to crises. While in a crises, following Keynes, saving can be an individual virtue and social vice (reducing aggregate demand, in turn leading to a deeper economic crisis), savings create a buffer for bad times, similar to the possession of property and physical capital. This requires a complete rethinking of the economic system, with lower economic activity, but also, following Taleb (2012), less painful downturns. Less inequality may bring more resilience, while health care should be considered a public good, which would imply a revolution in international co-operation. In this context, it should be remembered what Dag Hammarskjöld, the secretary general of the United Nations between 1953 and 1961 said (Hammarskjöld 1954). The United Nations (and in the current context, other 
global organizations such as the World Health Organization) are not meant to bring us into heaven, but to keep us out of hell.

Regarding the creation of new ideas for a more and open, cooperative and sustainable world, when making policy decisions, it may be good to consider two quotes of Mustafa Kemal Ataturk, the founder of the Turkish Republic (https://www.goodreads.com/author/quotes/2793859.Mustafa_Kemal_Atat_rk).

"Our true mentor in life is science."
"If one day, my words are against science, choose science."

Science, when properly carried out, does not ignore threats of pandemics, climate change, financial crashes, and so on. It seems rather to be political leaders, managers, decision makers, people in general ignoring existing information and signals, preparing the way for Black Swans to surprise the ignorant victims.

\section{References}

Acemoglu D., Robinson J.A. (2019),. The narrow corridor: states, societies, and the fate of liberty, Penguin Press, New York.

Alemanno A. (2020), The EU won't fix its democratic deficit with another top-down 'conference', "The Guardian", https://www.theguardian.com/commentisfree/2020/jan/21/eu-democratic-deficit-topdown-conference-verhofstadt [27.09.2020].

Amyotte P., Margeson A., Chiasson A., Khan F. (2014), There is no such a thing as a Black Swan process incident, Hazards 24 Institution of Chemical Engineers Symposium Series, 7-9 May 2014, Edinburgh, United Kingdom, pp. 12-21. [Non Refereed Conference Paper].

Bell E. (2017), Brexit and the illusion of democracy, "Socialism and Democracy", vol. 31 no. 3, pp. 52-73. doi: 10.1080/08854300.2017.1368888

Bonde J. (2011), The European Union's democratic deficit: How to fix it, "The Brown Journal of World Affairs", vol. 17, no. 2, pp. 147-162

Etzioni A. (2018), Law and society in a populist age - balancing individual rights and the common good, Bristol University Press, Bristol.

Glaubrecht, M. (2019), Das Ende des Evolution - Der Mensch und die Vernichtung der Arten (The end of evolution - Man and the annihilation of species), Bertelsmann Verlag, München.

Hammarskjöld, D. (1954), "Address by secretary-general Dag Hammarskjold at university of California convocation," UN department of public information, New York. 


\section{Johannes PLATJE, Grahame FALLON, Mehtet Baha KARAN et al. ...}

Harari, Y.N. (2020), The world after coronavirus, "Financial Times", 20 March. https://www.ft.com/content/19d90308-6858-11ea-a3c9-1fe6fedcca75.

Mavrozacharakis E., Tzagkarakis S.I., Kamekis A. (2017), Brexit: a consequence of the European social and democratic deficit (working paper), http://nbn-resolving.de/urn:nbn:de:0168-ssoar-51586-8, doi: 10.13140/RG.2.2.24452.12169.

Sorace M. (2018), The European Union democratic deficit: Substantive representation in the European Parliament at the input stage, "European Union Politics", vol. 19 no. 1, pp. 3-24. doi: $10.1177 / 1465116517741562$.

Taleb N.N. (2012), Antifragile - things that gain from disorder, Penguin Books, London.

Sotiris S. (2017), Democracy and democratic deficit in the European Union, "The New Federalist", https://www.thenewfederalist.eu/democracy-and-democratic-deficit-in-the-european-union?lang=fr [27.09.2020].

Will M. (2020), The CoViD-19 pandemic and the end of corporate risk management as we know it, "Central European Review of Economics and Management", vol. 4 no. 3, pp. 89-115. 